Article

\title{
Impacts of Urbanization of Mountainous Areas on Resources and Environment: Based on Ecological Footprint Model
}

\author{
Yu Ding ${ }^{1, *}$ and Jian Peng ${ }^{2}$ \\ 1 School of Economic and Management, Beijing Jiaotong University, Beijing 100044, China \\ 2 Laboratory for Earth Surface Processes, Ministry of Education, College of Urban and \\ Environmental Sciences, Peking University, Beijing 100871, China; jianpeng@urban.pku.edu.cn \\ * Correspondence: 12113120@bjtu.edu.cn; Tel.: +86-10-6407-2549
}

Received: 19 January 2018; Accepted: 4 March 2018; Published: 11 March 2018

\begin{abstract}
The rapid urbanization has exerted tremendous pressure on natural systems in mountains. As a measure of sustainable use of natural resources, ecological footprint is an important basis for judging whether the development of a country or region is within the bio-capacity. Taking Dali Bai Autonomous Prefecture as an example, this study comprehensively analyzes the impact of human activities on mountain resources and environment from the three aspects of urbanization, land use and ecological carrying capacity. The results show that Dali Prefecture with the urbanization rate of $33 \%$ is still in the accelerated stage of urbanization. The urban space presents the core-periphery feature, and the central city is the focus of human existence and living activities. The per capita ecological footprint is 1.14 ha higher than the ecological carrying capacity, meaning Dali Prefecture has an ecological deficit. This indicates that there is an uncoordinated state between urbanization and environment. Arable land is the main source of per capita ecological footprint in the prefecture. However, the urban expansion overly occupies the arable land in the plain sub-region, leading the arable land to an ecological deficit state. In the future, the development of the mountainous area should focus on the protection of arable land and choose a new sustainable path.
\end{abstract}

Keywords: mountainous areas; urbanization; ecological footprint; Dali Bai Autonomous Prefecture

\section{Introduction}

Urbanization is a worldwide phenomenon after the industrial revolution and a product of the development of modern industry and technological progress [1,2]. Industrialization represents a fundamental shift in the ways in which resources and environment are exploited and utilized, and its typical modes of social production and operation are: production mechanization; organization intensification; and mass consumption. Industrialization is precisely the economic connotation of the development of modern cities. Meanwhile, the emergence and development of cities are also a long-term endeavor and inevitable result of our continuous deepening development of earth's resources and the environment. Therefore, a modern city does not only serve as a place for gathering elements of population and consumption, but also plays a leading role in social production and environmental pollution through the agglomeration [3,4]. With the acceleration of industrialization and urbanization, the impact of human beings on natural resources has been gradually increased. The global crisis such as the shortage of resources and the deterioration of the environment has become a problem mankind has to face. If these problems are ignored and unsolved, they will further restrict the progress of human civilization. As China is a country with a large population and relatively fragile resources and environment, it's important to coordinate the relationship between urban development and the utilization of environment. 
Mountains are home to one tenth of the world's population and cover 25 percent of the earth's land surface [5]. The mountains have the resources of water, food, and energy. They shelter nearly half of the world's biodiversity [6]. In response to the challenge of urbanization, studying, protecting, and developing mountainous areas have become a major issue for the sustainable development of all countries [7]. Since 1998, in order to promote sustainable development of mountainous areas, the UNFAO as the responsible agency has done a great deal of work in cooperation with the United Nations Human Development Programme(UNDP), the United Nations Environment Programme (UNEP) and some governmental and non-governmental organizations. They compiled several reports on Sustainable Mountain Development and policy advice in the field of urbanization, economy and livelihoods, energy and infrastructure, education and capacity building [8,9].

China is one of the most mountainous countries. The mountainous areas (including hills and plateaus) of which account for about $70 \%$ of the country's territory, and the population in mountainous areas accounts for about $45 \%$ of the country's population [10]. Mountainous areas are important spatial carriers for the sustainable supply of people's activities, and also an important space for economic and social development in the future. The mountain topography in China is complex and diverse. The proportion of mountainous areas in the western region is generally large, where the extensive exploitation of resources, the large amount of traditional industries and the backward production methods lead to the waste of land resources and serious environmental pollution. There is a sharp decline in the service functions of mountain ecosystems [11]. Since the 1990s, the Chinese Academy of Sciences, Chongqing University, Northwestern University, etc. have carried out researches on the sustainable development of mountainous areas and achieved fruitful results. For example, Professor Guangyu Huang from Chongqing University established mountain urban science based on the planning and practical experience from 1959 to 2002 [12]. After a long period of studies on mountainous systems, Guojie Chen et al. (2010) found that there are not only differences in economic development among the eastern, central, and western regions in China, but also differences in the internal development of the mountainous areas, which is mainly due to the development of the secondary industry [13]. Yuluan Zhao et al. (2016) analysed Spatial Correlation between Type of Mountain Area and Land Use Degree in Guizhou Province [14]. Yang Yi et al. (2016) analysed Effects of Urbanization on Landscape Patterns in a Mountainous Area, and found urban development in mountainous areas should focus on the protection of arable land [15].

According to the National Bureau of Statistics of China, the urbanization rate in China reached $57.35 \%$, while the urbanization rate in the western region was $48.7 \%$, which was $10 \%$ below the national average in 2016. Among 31 provinces in China, there were 18 provinces whose urbanization rates were below the national average, 11 of which were in the western region [16]. Although the level of urbanization in the western region is only $46.5 \%$ [16], nearly half of the population in the western region now lives in cities. Fertile land is scarce as expanding industries and cities have engulfed the countryside, forcing the government to explore the differential development path of mountain urbanization. It is of great significance to coordinate the economic development in the mountainous areas with environmental protection on the basis of ecological carrying capacity.

In the narrow sense, ecological carrying capacity (ECC) refers to the maximum amount of biomass [17]. Since the 20th century, due to the continuous overexploitation of natural resources and deterioration of the ecological environment, the general conception of ECC came out [18]. ECC refers to the capacity of the ecosystem under the influence of various natural factors, social and cultural factors and their relations. The meaning of ECC includes two aspects. The first aspect refers to the ecological balance between supply and demand, which is the self-sustaining and self-regulating ability of the ecosystem. The second aspect is the positive and negative feedback from human activities on the ecosystem [19]. While ECC research is of great significance to sustainable social-economic-environment development, methods for estimating ECC are complicated and various. Representative methods include the ecological footprint (EF), natural vegetation net primary productivity estimation (NNP), and state-space methods, etc. EF analysis has received extensive attention and was widely used 
because of the results are straightforward, reliable and comparable [20]. EF methodology was proposed by Wackernagel and Rees, and has been continually improved by Wackernagel and other researchers [21]. It analyses the human demand for natural resources and ecosystem services, and the dependence of human life on those resources and services [22,23]. The key of the research is the combination of the land use with socio-economic metabolism mechanism by calculating the area of bio-productive land needed by mankind, including the area of biological production land required for consumption of renewable resources, infrastructure construction, and carbon dioxide emissions from the burning of fossil fuels (excluding marine absorption) [24-26]. Due to the prominent themes related to sustainable development such as the impact of human consumption on an ecosystem, the impact of urbanization on sustainable development and the redistribution of regional resources under environmental pressure, EF has been widely accepted and used in the assessment of sustainable development. K.B. Bicknell et al. (1998) proposed the use of a modified form of input-output analysis to calculate the EF. It makes explicit the link between the level of economic activity in a country and its corresponding impact on the environment. However, the input-output analysis was based on the static analysis of a single year; there were no complete and timely input-output tables in most regions [27]. H. Haberl et al. (2001) analysed the effect of different assumptions on yields that had on the results of EF for Austria 1926-1995. Although this study used different parameter values for different years to achieve a realistic measurement, the evaluation results of different years were less comparable [28]. Yung-Jaan Lee et al. (2016) presented Taiwan's ecological footprint from 2008-2011. Different parameter values for different years were also used by the authors according to the 2011 edition of the National Footprint Accounts (NFA) published by the Global Footprint Network (GFN). This enhanced the rationale for long-term series of EF studies. However, the mixed use of land as cropland and pasture land may result in double counting in the calculation, which caused a low systematic error [29]. Verhofstadt et al. (2016) expanded research content and scope, they investigated the relation between the EF and the subjective well-being at the individual level, using a questionnaire carried out in Flanders (Belgium) [30]. Since the mid-1970s, China has begun to experience ecological deficits, the scale of which has been expanding [31]. China's mountainous areas are complex, and researches on the carrying capacity of mountainous areas are rare. Scholars such as Yingmei Wu et al. (2006), Xudong Li (2013), and Yi Zhang et al. (2016) studied the resource and environment carrying process of mountainous areas in different spatial scales, respectively and evaluated the supporting capacity of the resources and environment in mountainous areas using the press-state-response (PSR) framework, the system dynamics model and the 3S technology [32-34]. After the Wenchuan Earthquake on 12 May 2008, many scholars analysed the particularity of mountain carrying capacity and proposed that the size and spatial pattern of mountainous areas should be adjusted [35]. In general, China has not yet conducted an in-depth study on the ECC of mountainous areas.

In the present study, our goals were to: (1) analyze the changes of urbanization in Dali Prefecture, thus understanding China's mountain area development better; (2) evaluate land use characteristics, thus identifying and assessing the land use structure and spatial differentiation of mountain area; and (3) calculate the ecological pressure of urbanization by using an EF model, thus improving the socioeconomic development strategy.

\section{Materials and Methods}

\subsection{Study Area}

In order to understand the impact of mountain urbanization on resources and environment, Dali Prefecture of Yunnan Province was selected for observation. Established in 1956, the Prefecture is the only Bai Autonomous Prefecture in China, located in the central west of Yunnan Province, $398 \mathrm{~km}$ away from the provincial capital of Kunming (Figure 1). The Prefecture is located at the junction of Yunnan-Guizhou Plateau and the Hengduan Mountains, with an average elevation of $1974 \mathrm{~m}$. It is under a subtropical low latitude plateau monsoon climate, with the average annual rainfall of about 
$1000 \mathrm{~mm}$ and the average annual sunshine time of $2345 \mathrm{~h}$ [36]. Due to the complex topography and vast elevation difference, the vertical difference of climate is significant. Dali Prefecture has a land area of $29,459 \mathrm{~km}^{2}$ with mountain areas accounting for $93.4 \%$. The land area of steep slopes with the inclination above 25 degrees and the gentle slopes with the inclination of 8-25 degrees occupies $41 \%$ and $51 \%$ of the total area respectively. The plain sub-region area with the inclination between 0 and 8 degrees occupies only $6.6 \%$ of the total area [37]. According to the statistics of the Dali State Planning Bureau, the plain sub-region area has $57.8 \%$ of the settlements and is the land carrying area with relatively concentrated population, relatively active economy, and urban development.

Due to the influences of the topography and the conditions of multi-ethnic areas, the urbanization of the western region of China has long been characterized by its special status and its own development. Dali Prefecture as a typical mountain city in the west of China located in the hinterland and far away from the sea is relatively backwardness and poor. The urbanization has an increasing demand for land resources, and there is an urgent need to further study the relationship between urbanization, resources and environment.

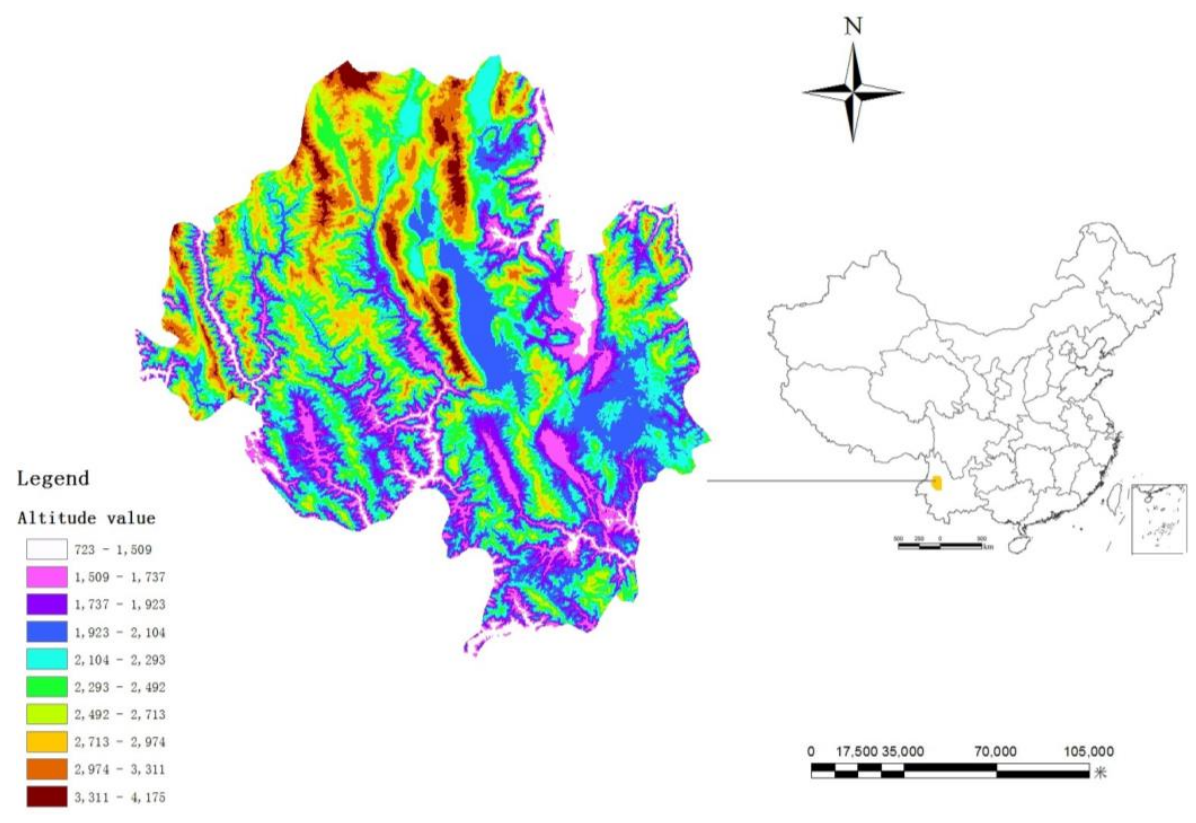

Figure 1. Location of Dali Prefecture.

\subsection{Study Methods}

The EF model is effective to measure the sustainability of regional development by comparing the EF of regional development with the ECC of natural ecosystems. EF refers to a land area of the biological production which provides resources for development of humans and absorbs waste [38]. ECC is the capacity of ecological footprint supply with the study of bio productive land. The method uses the land area as the unit of measurement, and uses the average output data to convert various kinds of resource consumption into corresponding biological production land areas in proportion. The land use types include arable land, woodland, grassland, fossil fuel land, built-up land and water, etc. Because of the varying biological productivity of these types of land, an equilibrium factor is used to convert land areas with different bio-productivity into areas with a globally averaged ecological productivity. Yield factors are introduced to compare the productivity of the same type of bio-production land per unit area in different countries or regions. The ECC is represented by the ecological deficit or surplus, and the former refers to the state of ecological footprint exceeding the ecological supply, while latter is the opposite [21,39]. The formula is as follows:

$$
E F=N \times e f=N \times \sum_{j=1}^{n} c_{j} / p_{j}
$$




$$
\begin{aligned}
& E C C=N \times e c c=N \times \sum_{j=1}^{6} a_{j} \times r_{j} \times y_{j} \\
& E D(E R)=E F-E C C=N \times(e f-e c c)
\end{aligned}
$$

where EF is the total ecological footprint (ha); $N$ is the total population; $e f$ is the per capita ecological footprint (ha/per); $c_{j}$ is per capita consumption of goods of class; $p_{j}$ is the average production capacity of class $j$ consumption goods per unit area; ECC is the total ecological carrying capacity in the region (ha); ecc is the per capita ecological carrying capacity (ha/per); $a_{j}$ is the actual per capita possession of biological production of land area in class $j ; r_{j}$ is the equivalence factor of class $j$ land, and $y_{j}$ is the yield factor of class $j$ land; ED is the ecological deficit (ha); ER is the ecological surplus (ha). The "equivalence factor" and "yield factor" are based on the values in the report of Ecological Footprints of Nations [39] published by Wachernagel.

\subsection{Data Sources}

Data for urbanization and EF studies conducted in this paper is from the Dali Statistical Yearbook. The land use data is interpreted from Landsat Enhanced Thematic Mapper Plus (ETM+) satellite scenting in 2000 and 2010 and converted to a vector format for manual correction against Google Earth. Land use is divided into eight kinds of land, namely, arable land, woodland, grassland, built-up land, water, snow and ice covered land, unused land and other types.

\section{Results}

\subsection{Urbanization}

From 1956 to 2010, the urban population increased from 112,100 to 114,180, and the urbanization rate grew from $6 \%$ to $33 \%$ with an average annual increase of 0.51 percentage points. Figure 2 showed that since the 1990s, the urbanization in Dali Prefecture had entered a period of rapid development, with a net increase of about 90,000 urban population per year, keeping a gradual increase in pace with the average level in Yunnan Province. Its urbanization has entered a period of accelerated development. However, the level of urbanization in Dali Prefecture was rather low in China. In 2010, the urbanization rate of Dali Prefecture was equivalent to the average level of China in 1998, and its urbanization rate lagged behind that of the whole country for about 12 years.

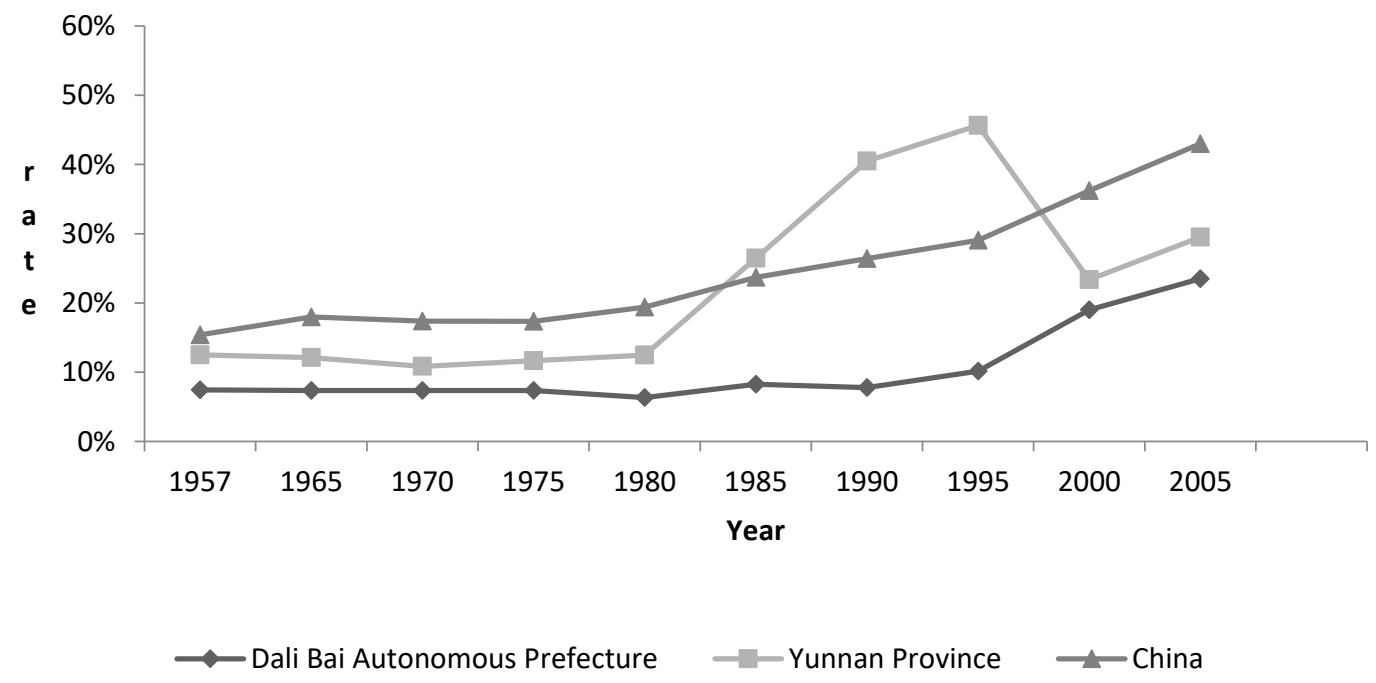

Figure 2. Urbanization rate comparison from 1957-2005.

The development of urban system in Dali Prefecture was not balanced. There were 70 towns in Dali Prefecture with the urban density of 39 people $/ \mathrm{km}^{2}$. The size of the urban population could 
be divided into the three grades of 200,000 or more, 150,000-200,000, 1-50,000 (Table 1), the ratio of the number of towns at each grade was 1:17:50. Only one city had a population of more than 200,000 , and the number of cities with the population of about 100,000 was scarce, while cities with a population of 50,000 or less account for $73.5 \%$. The central urban area depending on the location and environmental advantages of the Cangshan Mountain and the Erhai Lake had always been the center of Dali's economic and social activities. In 2010, the population of the central urban area reached 241,000 with an urbanization rate of $60 \%$, while the size of non-agricultural population and urban economic output accounted for $54 \%$ and $38 \%$ of the entire region, respectively, taking the lead in the steady development of urbanization. With the Cangshan Mountain and the Erhai Lake as the boundary, the development of the eastern region and the western region differed greatly (Figure 3). There were many plain sub-regions in the east, enabling high accessibility to transportation and rapid economic development. In 2010, the land area and cultivated area of the eastern region were $47 \%$ and $56 \%$ of that of Dali Prefecture respectively. GDP, retail sales of social consumer goods and urban population account for nearly $80 \%$ of Dali Prefecture, respectively. The economic linkage between the eastern and western regions was not prominent, resulting in the fact that the organic development of the region had not yet taken shape.

Table 1. Urban hierarchical structure in 2010.

\begin{tabular}{ccc}
\hline City Scale Grad & Number of Cities & Population (Ten Thousand) \\
\hline$>200$ thousand people & 1 & 24.1 \\
$50-200$ thousand people & 17 & 117.9 \\
$10-50$ thousand people & 50 & 152.3 \\
\hline
\end{tabular}

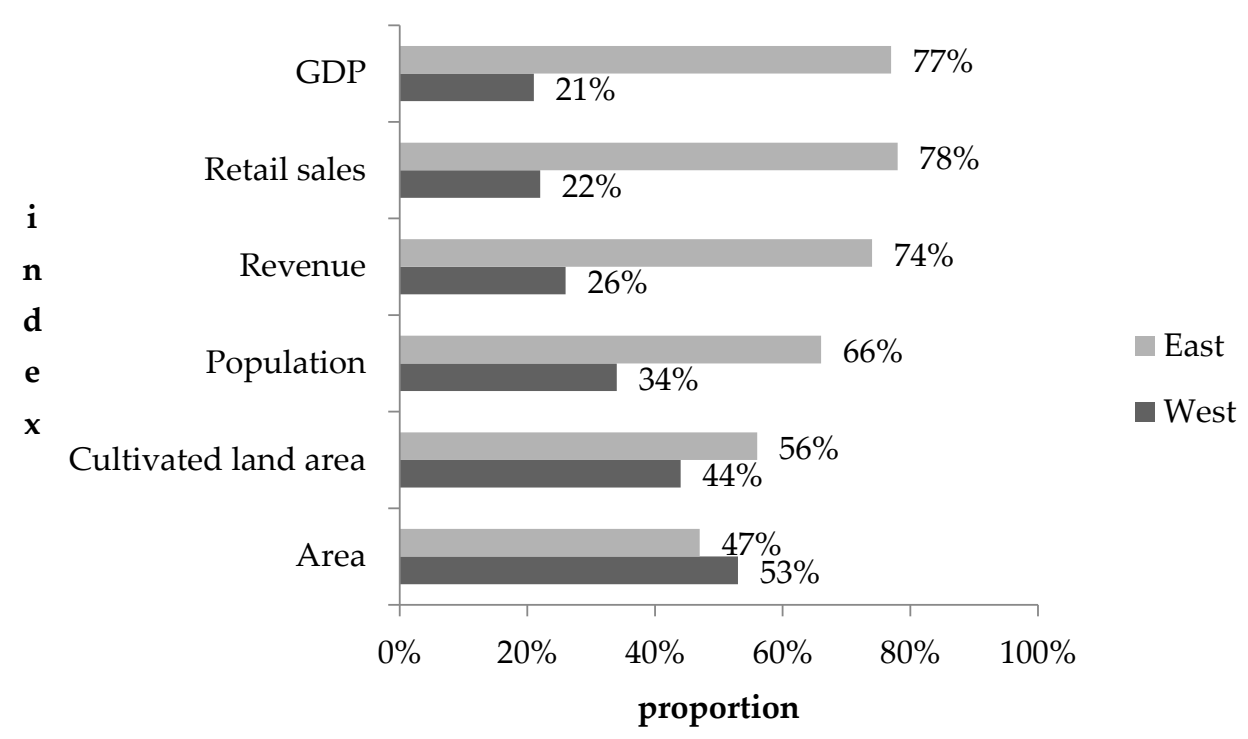

Figure 3. The spatial difference in input and output effects of urbanization in 2010.

\subsection{Land Use}

Land use change was an important reflection of the evolution of the ecological environment. Table 2 showed that non-agricultural built-up land in Dali Prefecture increased by 23,000 ha, with an average annual increase of $5.4 \%$. In recent years, with the rapid economic and social development and the progress of urbanization, the growth of built-up land was substantially increased. In 2010, the woodland and grassland accounted for $82.32 \%$ of the total area, and other types of land $17.68 \%$. Compared with 2000, the woodland and grassland remained the major types of land use, and the area of arable land decreased significantly, with a decrease of $2.3 \%$. 
The land-use transfer matrix was an important tool for analyzing the change relationship between land-use types of the same area in different periods. Table 3 showed that the arable land area was in a decline in status, mainly was transformed into woodland, grassland, unused land, and built-up land. Excluding the influence of the spectral content of the image interpretation, the built-up land occupation and the conversion of cropland to forestland were the most important factors for the reduction of arable land. The increase of woodland was mainly attributed to the increase of vegetation coverage of arable land and grassland, and the reduction of grassland area was mainly because it was transformed into woodland, which was achieved in projects for reforesting formerly cultivated land and protecting natural forests. The increase of built-up land was mainly from occupying arable land and grassland, mostly of which were in the gentle terrain, reflecting the prominent demand of Dali Prefecture for economic development. The decreased water turned into arable land and grassland, indicating the severe situation of wetland protection.

Table 2. Land use status change between 2000 to 2010.

\begin{tabular}{cc}
\hline Land Type & Area (ha) \\
\hline Arable land & $-64,969.2$ \\
Woodland & $144,066.3$ \\
Grassland & $-75,598.7$ \\
Built-up land & 308.9 \\
Water & -4347.0 \\
Ice and snow cover & $-16,211.4$ \\
Unoccupied land & $26,089.7$ \\
Other land & -9348.4 \\
\hline
\end{tabular}


Table 3. Land use status transfer matrix between 2000-2010.

\begin{tabular}{|c|c|c|c|c|c|c|c|c|}
\hline Type & Arable Land & Woodland & Grassland & Built-Up Land & Water & Ice and Snow Cover & Unoccupied Land & Other Land \\
\hline Arable land & $159,398.19$ & $69,883.92$ & $42,567.48$ & 3651.21 & 1177.65 & 9503.73 & $18,343.08$ & 855.9 \\
\hline Woodland & $103,690.35$ & $1,423,682.55$ & $227,007.63$ & 2310.21 & 1767.87 & 7299.45 & $22,534.56$ & $10,047.42$ \\
\hline Grassland & $69,573.51$ & $142,829.1$ & $251,010.27$ & 8220.42 & 2457.54 & 397.98 & $42,784.47$ & 4360.5 \\
\hline Built-up land & 4569.03 & 2737.35 & 6838.65 & 9865.08 & 1613.43 & 35.55 & 1557.54 & 223.65 \\
\hline Water & 319.68 & 1247.94 & 734.4 & 817.83 & $30,701.79$ & 15.48 & 59.13 & 364.32 \\
\hline Ice and snow cover & 2.43 & 369.99 & 558.81 & 29.25 & 4.05 & 397.98 & 2.07 & 57.6 \\
\hline Unoccupied land & $22,143.24$ & $13,428.09$ & $73,389.51$ & 1998 & 391.5 & 46.89 & $22,451.94$ & 302.58 \\
\hline Other land & 1198.62 & 2334.69 & 2037.96 & 253.89 & 497.88 & 312.75 & 327.69 & $2,118,151.44$ \\
\hline
\end{tabular}




\subsection{Ecological Carrying Capacity}

The per capita ECC of Dali Prefecture was generally high, and the types of land with low carrying capacity were scattered across the whole area. The per capita ECC of various types of land varies greatly (Table 4). Among them, the per capita ECC of arable land was the highest, i.e., 0.583 ha, accounting for $44.02 \%$ of the total; the second was woodland, which was 0.490 ha. The lowest was the unused land, because of its equivalence factor and yield factor were 0 . In addition, the per capita ECC of water was $0.003 \mathrm{ha}$, mainly due to the small area of water and the relatively low equivalence factor. The spatial distribution of per capita ECC was different which was showed in Figure 4. The ECC in the western region was lower than that in the eastern region, mainly due to the population of the eastern region being large.

Table 4. Ecological carrying capacity per capita.

\begin{tabular}{ccccc}
\hline Land Use Category & $\begin{array}{c}\text { Equivalence } \\
\text { Factor }\end{array}$ & $\begin{array}{c}\text { Yield } \\
\text { Factors }\end{array}$ & $\begin{array}{c}\text { Land Area } \\
\text { (ha/per) }\end{array}$ & $\begin{array}{c}\text { Carrying Capacity } \\
\text { (ha/per) }\end{array}$ \\
\hline Grassland & 0.5 & 6.5 & 0.054 & 0.176 \\
Arable land & 2.8 & 1.49 & 0.140 & 0.583 \\
Built-up land & 2.8 & 1.49 & 0.017 & 0.07 \\
Woodland & 1.1 & 0.8 & 0.558 & 0.490 \\
Water & 0.2 & 1 & 0.014 & 0.003 \\
Unoccupied land & 0 & 0 & 0.005 & 0 \\
Total & & & & 1.324 \\
Total (Deduct 12\% & & & & 1.165 \\
biological diversity) & & & & \\
\hline
\end{tabular}

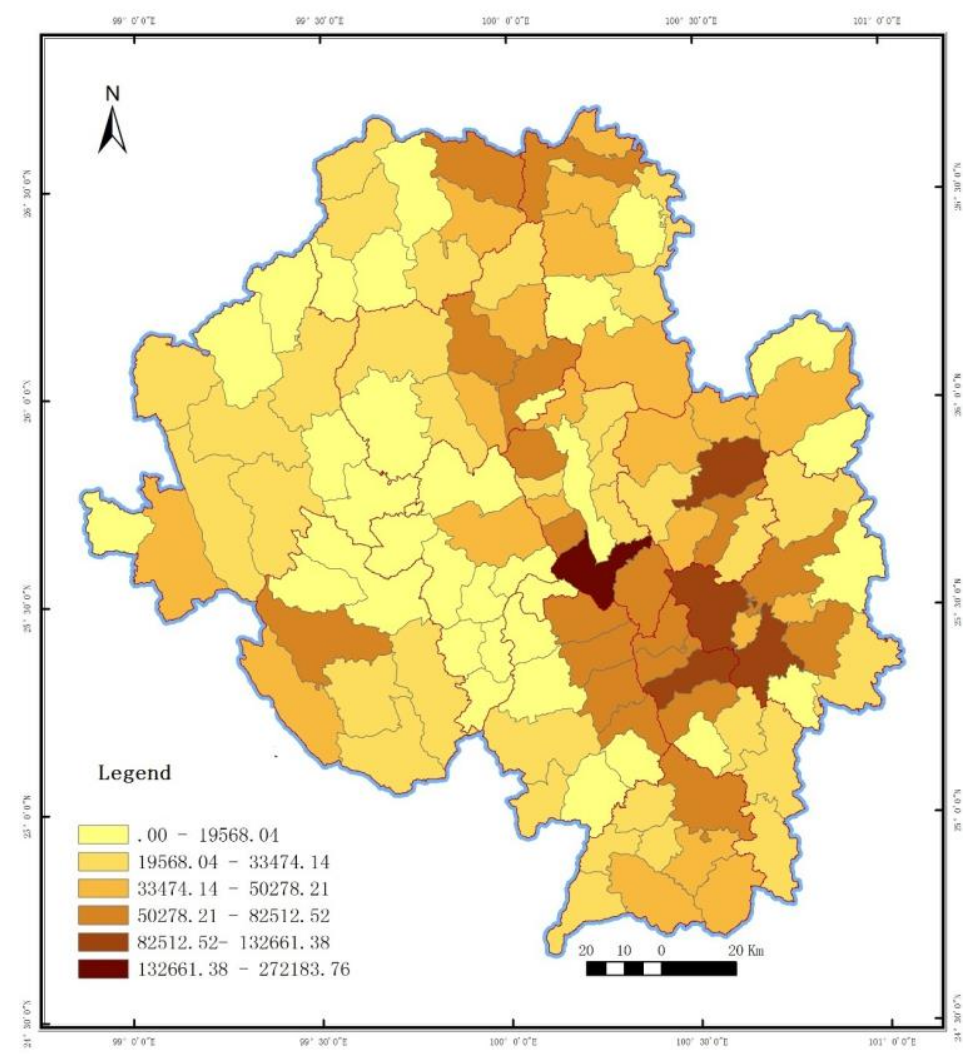

Figure 4. Distribution of ecological carrying capacity. 
Table 5 showed that the per capita EF of Dali Prefecture was 2.31 ha, which was slightly higher than China's average EF (2.2 ha) [21]. However, the ED of Dali Prefecture reached 1.14 ha, which indicated an unsustainable development. The comparison between the per capita EF and ECC was shown in Figure 3. Among them, the per capita EF of arable land reached 1.64 ha, which was the main source of per capita EF in the prefecture, accounting for $70.91 \%$ of the total. The least was built-up land, which was 0.001 ha. In terms of supply and demand, the built-up land and woodland were in surplus of 0.07 ha and 0.47 ha respectively among the six types of land. The ED occurred in the arable land, grassland, water area and fossil fuel land. Overall, Dali prefecture was in the state of ED, with the largest proportion of the Dali city in the East (16.94\%), and the least of Yangbi in central Dali Prefecture (2.93\%). The spatial difference of the ED was obvious, and the eastern region was higher than the western region (Figure 5).

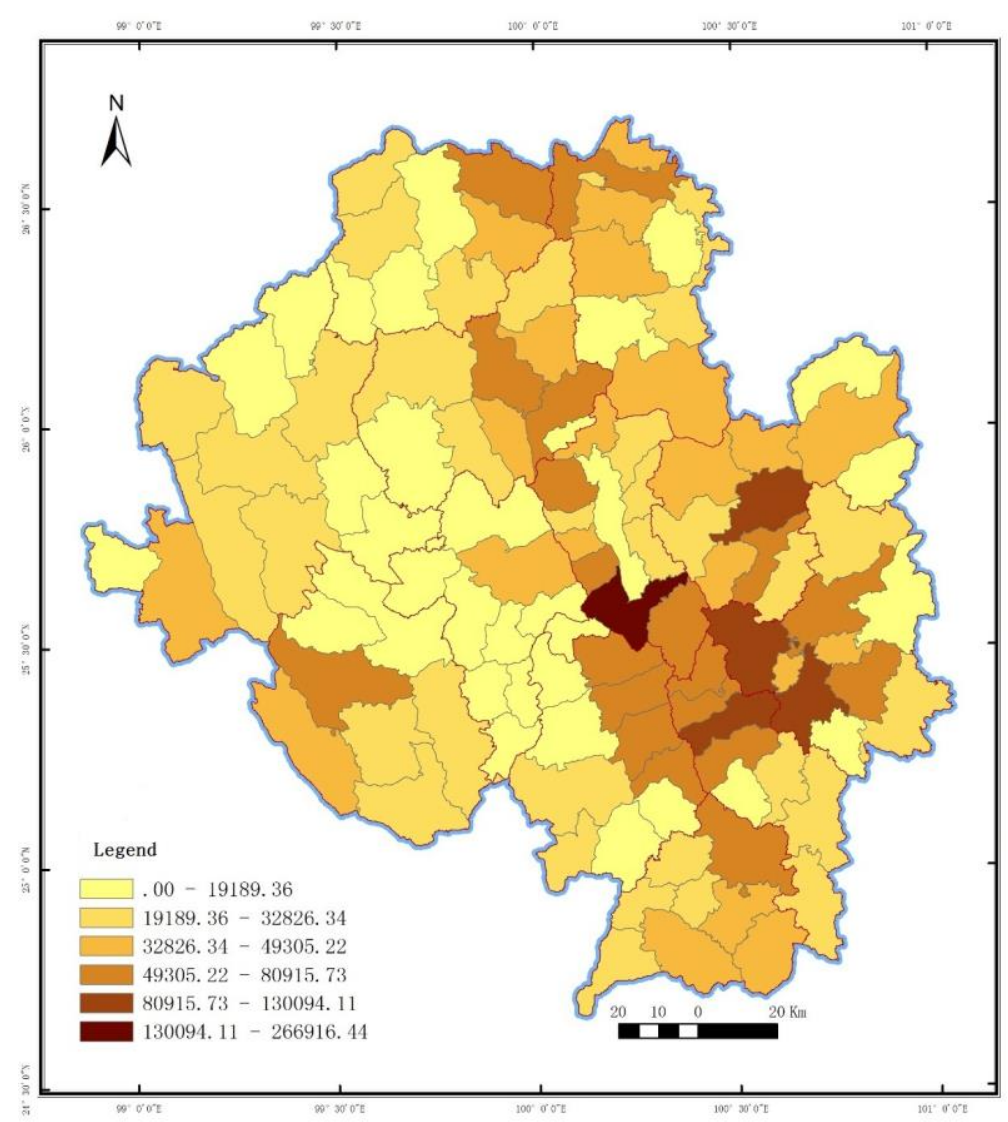

Figure 5. Distribution of ecological footprint ecological deficit. 
Table 5. Ecological carrying capacity evaluation.

\begin{tabular}{|c|c|c|c|c|c|c|c|c|c|}
\hline \multirow[b]{2}{*}{ Land Use Category } & \multicolumn{4}{|c|}{ Carrying Capacity (Supply) } & \multicolumn{3}{|c|}{ Ecological Footprint (Demand) } & \multirow{2}{*}{$\begin{array}{l}\text { The Difference of } \\
\text { Carrying } \\
\text { Capacity (ha/per) }\end{array}$} & \multirow{2}{*}{$\begin{array}{l}\text { Carrying } \\
\text { Capacity pe } \\
\text { Capita }\end{array}$} \\
\hline & $\begin{array}{l}\text { Equivalence } \\
\text { Factor }\end{array}$ & $\begin{array}{l}\text { Yield } \\
\text { Factors }\end{array}$ & $\begin{array}{c}\text { Land Area } \\
\text { (ha/per) }\end{array}$ & $\begin{array}{c}\text { Carrying } \\
\text { Capacity (ha/per) }\end{array}$ & $\begin{array}{l}\text { Equivalence } \\
\text { Factor }\end{array}$ & $\begin{array}{c}\text { Land Area } \\
\text { (ha/per) }\end{array}$ & $\begin{array}{c}\text { Ecological } \\
\text { Footprint (ha/per) }\end{array}$ & & \\
\hline Grassland & 0.5 & 6.5 & 0.05 & 0.17 & 0.50 & 0.37 & 0.18 & 0.01 & deficit \\
\hline Arable land & 2.8 & 1.5 & 0.14 & 0.58 & 2.80 & 0.58 & 1.64 & 1.05 & deficit \\
\hline Built-up land & 2.8 & 1.5 & 0.02 & 0.07 & 2.80 & 0.00 & 0.00 & -0.07 & surplus \\
\hline Woodland & 1.1 & 0.8 & 0.56 & 0.49 & 1.10 & 0.02 & 0.02 & -0.47 & surplus \\
\hline Water & 0.2 & 1 & 0.01 & 0.00 & 0.20 & 0.40 & 0.08 & 0.08 & deficit \\
\hline Fossil energy land & 1.1 & 0 & 0 & 0 & 1.10 & 0.35 & 0.39 & 0.39 & deficit \\
\hline Unoccupied land & 0 & 0 & 0.01 & 0 & 0 & 0 & 0 & 0.00 & - \\
\hline Total & & & & 1.32 & & & 2.31 & - & - \\
\hline $\begin{array}{c}\text { Total (Deduct } 12 \% \\
\text { biological diversity) }\end{array}$ & & & & 1.17 & & & & 1.14 & deficit \\
\hline
\end{tabular}




\section{Discussion}

The generation, development, and evolution of cities depend entirely on the extent to which mankind uses and develops natural resources and the environment. Urban agglomeration of space does not only make the city become the most powerful impetus of economic development, but also changes the natural ecosystem. China, which is rapidly developing, is still at an accelerated stage of industrialization and urbanization. Industrialization and urbanization often lead to greater EF challenges, which are also the stage that developed countries have experienced. The stability of the mountain ecosystem is related to the sustainable development of China in the future [35]. In the meantime, due to the limitation of mountainous terrain in western China, the economic development of the region has lagged behind in China for a long time. The development of mountain cities faces the same problem that many underdeveloped mountain areas in the world are experiencing in their development, namely, how to achieve sustainable growth under unfavorable natural conditions.

Dali Prefecture is a typical mountain city in China. Researches show that about $33 \%$ of the population lived in the city in 2010. Along with the deepening of its urbanization, Dali Prefecture is experiencing the single-core growth pattern. At present, the central urban area's lack of enough attraction has limited its spillover to its hinterland. The mountainous terrain has led to the unbalanced distribution of urban system in the prefecture. Therefore, the strategy of balanced spatial development is unrealistic in mountainous areas, meaning the polarization of a single center will not change for a long time. With the accelerated development of urbanization and the continuous expansion of urban areas, the resources and environment per capita will grow, resulting in the increasingly prominent scarcity of land resources. The spatial expansion of built-up land will have a profound impact on the evolution of the ecological environment.

The EF of the prefecture has exceeded the bio-capacity, and the sustainability of resources is facing increasingly serious challenges. Low population density and slow economy development result in low demand for construction, which brings about a surplus of the carrying capacity of built-up land. Under the background of the acceleration of urbanization, people's consumption of grain-based agricultural products and the consumption of animal products are on the rise and require a large amount of arable land and grassland. On the other hand, the resource based economy has a high dependence on mining and processing industry, and the area of fossil energy land increases accordingly. Thus, the rapid development of urbanization has a greater impact on changes in EF and its elements. A large number of arable lands were occupied for urban construction, which has surpassed the mountainous environment conditions. At the same time, the built-up land in the plain sub-region is used inefficiently. The serious situation not only aggravated the human contradiction, but also caused great ecological security problems.

EF methodology provides a new perspective for the study of mountain ECC, which is helpful for revealing the relationship between mountain ecology and the process of urbanization. The results are in good agreement with most scholars using different methods for carrying capacity assessment. The population size and land use structure are the key elements in evaluating the ECC $[33,40,41]$. When there is ecological deficit in the developed areas, the direct effect of the ecological environment can be alleviated by inputting the required resources through the outside world. However, Dali prefecture is in an underdeveloped western region, and its surplus natural population tends to be over-utilized by local resources. Therefore, ecological deficit on the mountain environment is fatal, which can't be ignored.

\section{Conclusions}

This study showed that urbanization in Dali Prefecture had been growing at a steady rate since 1956. After entering the 21st century, the urbanization had been growing rapidly. Meanwhile, the EF had also been rapidly increasing. In 2010, the per capita EF was higher than the per capita ECC, and the ecological supply had a deficit. Although the environment was good locally, the bio-productive land could not meet the demand for the renewable energy consumed by its population. Urbanization was a 
main process in the region land use. It must address the problem of urban sprawl in mountainous areas. The EF exerted greater pressure on the sustainable development of the mountainous areas.

The mountain topography determines that the future urban expansion cannot continue to occupy a large amount of arable land, and this also determines that Dali Prefecture should choose a new sustainable path, instead of following the traditional extensive urban expansion mode. It is proposed from the following three aspects. First, increase the speed and quality of urbanization. According to the growth pole theory, we should foster a reasonable urban system to strengthen the areas with higher ECC and greater development potential in the eastern region of Dali Prefecture. Based on the interaction of natural and human being factors, polycentric and multi-group urban development will replace the linear expansion along Erhai Lake to avoid urban sprawl in Dali Prefecture. Second, reducing the ED requires increasing the efficiency of land production in a unit area. The mountain ecosystem in Dali Prefecture is inherently fragile and human activities have drastically changed the local eco environment. In light of the above reasons, we need to make effective use of non-agricultural land and vigorously develop agriculture with distinctive local characteristics, such as forest fruit industry, leisure and sightseeing, agriculture, ecological agriculture under contour hedgerow in small watershed, and so on. This is more conforming to the law of scientific growth than pursuing of the expansion of grain production. However, with the development of urbanization, the demand for food will increase. Besides, whether it is to develop the non-agricultural industry or adjust the agricultural structure, it is bound to be restricted by two major factors: the shortage of grain in the plain area and the shortage of funds. Under such circumstances, we can develop stereoscopic agriculture based on the advantages of mountain resources, which will improve agricultural increment and farmer's income. Third, improve production efficiency. The utilization of resources in Dali Prefecture which is mainly in primary processing has low added value of resource products. In the future, it can draw lessons from the mode of "small and fine economic mode" of Switzerland in the economy of mountainous areas to guarantee the development of resource products from the aspects of capital, technology, and human resources, increase the processing depth of resources, and turn resource advantages into competitive advantages, especially deep processing of biological resources.

Acknowledgments: This study was financially supported by the National Natural Science Foundation of China (NSFC)(No.41571518). The author thanks the anonymous referees for their valuable comments.

Author Contributions: Jian Peng analysed the data and contributed analysis tools; Yu Ding wrote the paper, and handled all versions of the manuscript submission.

Conflicts of Interest: The authors declare no conflict of interest.

\section{References}

1. Fujii, T. Industrization, Urbanization and economic growth. Econ. Rev. 1966, 17, 368-372.

2. Bertinelli, L.; Black, D. Urbanization and growth. J. Urban Econ. 2004, 56, 80-96. [CrossRef]

3. Schatzki, T. Sustainable Cities: Urbanization and the Environment in International Perspective; Stren, R., White, R., Whitney, J., Eds.; Westview Press: Boulder, CO, USA, 1992.

4. Lei, Z. The Resource-Environment Base for China's Urbanization; Science Press: Beijing, China, 1980; p. 52. (In Chinese)

5. Löffler, J.; Anschlag, K.; Baker, B.; Finch, O.-D.; Wundram, D.; Diekkrüger, B.; Schröder, B.; Pape, R.; Lundberg, A. Mountain ecosystem response to global change. Erdkunde 2011, 6, 189-213. [CrossRef]

6. Payne, K.; Warrington, S.; Bennett, O. High Stakes: The Future for Mountain Societies; London England Panos Institute: London, UK, 2002; p. 6.

7. Blyth, S.; Groombridge, B.; Lysenko, I.; Miles, L.; Newton, A. Mountain Watch, Environmental Change and Sustainable Development in Mountains; UNEP-WCMC: Cambridge, UK, 2002; p. 11.

8. Mapping the Vulnerability of Mountain Peoples to Food Insecurity. Available online: https:/ /www.researchgate. net/publication/312189900_Mapping_the_vulnerability_of_mountain_peoples_to_food_insecurity (accessed on 1 January 2018). 
9. Report of the World Summit on Sustainable Development. Available online: http:/ /www.un-documents. net/jburgpln.htm (accessed on 1 June 2017).

10. Wei, D.; Genwei, C.; Anban, W. The conception of mountain science development in China. Discip. Dev. 2008, 23, 156-161. (In Chinese)

11. Wei, D. Discussion on mountain area resource and environment carrying capacity. Geogr. Res. 2010, 29, 959-969. (In Chinese)

12. Guangyu, H. Theory of Mountain Urbanology; China Architecture \& Building Press: Beijing, China, 2006 ; p. 6. (In Chinese)

13. Guojie, C. The trend and main task of study on the development of mountain areas in China. J. Mt. Sci. 2006, 24, 531-538. (In Chinese)

14. Zhao, Y.; Li, X. Spatial correlation between type of mountain area and land use degree in Guizhou province, China. Sustainability 2016, 8, 849. [CrossRef]

15. Yi, Y.; Zhao, Y.; Ding, G.; Gao, G.; Shi, M.; Cao, Y. Effects of urbanization on landscape patterns in a mountainous area: A case study in the Mentougou district, Beijing, China. Sustainability 2016, 8, 1190. [CrossRef]

16. China Statistical Yearbook in 2017. Available online: http://www.stats.gov.cn/tjsj/ndsj/2017/indexch.htm (accessed on 5 January 2018). (In Chinese)

17. Park, R.E.; Burgess, E.W. Introduction to the Science of Sociology; University of Chicago Press: Chicago, IL, USA, 1921; p. 43.

18. Clark, W.C.; Crutzen, P.J.; Schellnhuber, H.J. Science for Global Sustainability: Toward a New Paradigm. SSRN Electron. J. 2005, 15, 837-868. [CrossRef]

19. Xue, Q.; Song, W.; Zhang, Y.; Fengyun, M. Research Progress in Ecological Carrying Capacity: Implications, Assessment Methods and Current Focus. J. Resour. Ecol. 2017, 8, 514-525.

20. Jian, P.; Jiansheng, W.; Yiyi, J.; Minting, Y. Shortcomings of applying ecological footprints to the ecological assessment of regional sustainable development. Acta Ecol. Sinaca 2006, 26, 2716-2722.

21. Wackernagel, M.; Rees, W. Our Ecological Footprint: Reducing Human Impact on the Earth; New Society Publishers: Gabriola Island, BC, Canada, 1996; p. 160.

22. Chen, G.Q.; Chen, B. Resource analysis of the Chinese society 1980-2002 based on exergy-Part 1: Fossil fuels and energy minerals. Energy Policy 2007, 35, 2038-2050. [CrossRef]

23. Haberl, H.; Wackernagel, M.; Krausmann, F.; Erb, K.; Monfreda, C. Ecological footprints and human appropriation of net primary production: A comparison. Land Use Policy 2004, 21, 279-288. [CrossRef]

24. Galli, A.; Kitzes, J.; Wermer, P.; Wackernagel, M.; Niccolucci, V.; Tiezzi, E. An exploration of the mathematics behind the ecological footprint. Int. J. Ecodyn. 2007, 2, 250-257. [CrossRef]

25. Kitzes, J.; Galli, A.; Baglianin, M.; Barrett, J.; Dige, G.; Ede, S.; Erb, K.; Giljum, S.; Haberl, H.; Hails, C.; et al. A research agenda for improving national ecological footprint accounts. Ecol. Econ. 2009, 68, 1991-2007. [CrossRef]

26. Wackernagel, M.; Schulz, N.B.; Deumling, D.; Linares, A.C.; Jenkins, M.; Kapos, V.; Monfreda, C.; Loh, J.; Myers, N.; Norgaard, R.; et al. Tracking the ecological overshoot of the humane conomy. Proc. Natl. Acad. Sci. USA 2002, 99, 9266. [CrossRef] [PubMed]

27. Bicknell, K.B.; Ball, R.J.; Cullen, R.; Bigsby, H.R. New methodology for the ecological footprint with an application to the New Zealand economy. Ecol. Econ. 1998, 27, 149-160. [CrossRef]

28. Haberl, H.; Erb, K.H.; Krausmann, F. How to calculate and interpret ecological footprints for long periods of time: The case of Austria 1926-1995. Ecol. Econ. 2001, 38, 25-45. [CrossRef]

29. Yung-Jaan, L.; Li-Pei, P. Taiwan's Ecological Footprint (1994-2011). Sustainability 2014, 6, 6170-6187.

30. Verhofstadt, E.; Ootegem, L.V.; Defloor, B.; Bleys, B. Linking individuals' ecological footprint to their subjective well-being. Ecol. Econ. 2016, 127, 80-89. [CrossRef]

31. Living Planet Report 2012-Biodiversity, Biocapacity and Better Choices. Available online: http:/ / wwf.panda. org/about_our_earth/all_publications/living_planet_report/ (accessed on 18 July 2017).

32. Yingmei, W.; Ya, L.; Lei, Z. Evaluation of regional resource-environment base supportability: The cse of southwest China. Areal Res. Dev. 2006, 25, 20-23. (In Chinese)

33. Xudong, L. Tempo-spatial analysis of the relative carrying capacity of population and resources in Wumeng mountainous area of Guizhou. Geogr. Res. 2013, 32, 233-244. (In Chinese) 
34. Yi, Z.; Yinfu, L.; Zenfeng, C. Research on resource environmental bear capacity of Yunnan mountain area-A case study of Yunnan Longchuan. Yunnan Geogr. Environ. Res. 2016, 28, 29-34. (In Chinese)

35. Jie, F. Fundamental function in resource environment carrying capacity evaluation in the state planning for Post-Wenchuan earthquake restoration and reconstruction. Bull. Chin. Acad. Sci. 2008, 23, 387-392. (In Chinese)

36. The General Situation of Dali Prefecture. Available online: http:/ / www.dali.gov.cn/dlzwz/5116653226157932544/ 20121126/267789.html (accessed on 17 February 2018). (In Chinese)

37. Local Chronicles of Dali Prefecture. The Statistical Yearbook of Dali Prefecture in 2011; Yunnan National Publisher: Yunnan, China, 2011. (In Chinese)

38. Blasi, E.; Passeri, N.; Franco, S.; Galli, A. An ecological footprint approach to environmental-economic evaluation of farm results. Agric. Syst. 2016, 145, 76-82. [CrossRef]

39. Wackernagel, M.; Yount, J.D. The ecological footprint: An indicator of progress toward regional sustainability. Environ. Monit. Assess. 1998, 51, 511-529. [CrossRef]

40. Kan, Z.; Jie, F. Characteristics and influence factors of resources and environment carrying capacity in underdeveloped areas of China. Geogr. Res. 2015, 34, 39-52. (In Chinese)

41. Hong, T.; Degang, Y.; Cong, S.; Shaohong, W.; Weidong, L.; Li, M.; Xiaofeng, W.; Yunhe, Y.; Jing, L. Synthesized assessment of eco-environment in the economic belt on the northern slope of the Tianshan Mountains based on AHP. Arid Land Geogr. 2010, 33, 629-664. (In Chinese)

(C) 2018 by the authors. Licensee MDPI, Basel, Switzerland. This article is an open access article distributed under the terms and conditions of the Creative Commons Attribution (CC BY) license (http://creativecommons.org/licenses/by/4.0/). 